\title{
A propos d'Afrique du Sud, d'entomologie et d'autres choses
}

\section{Jean Martin}

Membre de la rédaction

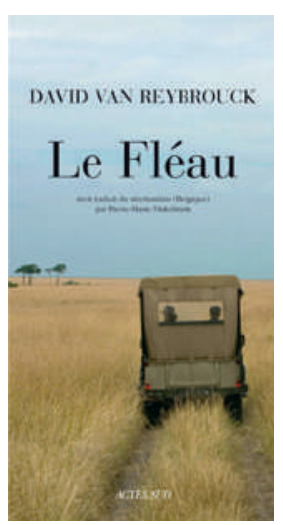

David van Reybrouck

\section{Le Fléau}

Arles: Actes Sud; 2008.

416 pages. $16.10 \mathrm{CHF}$. ISBN 978-2-7427-7553-8
Je ne sais plus qui m'a offert ce livre, il y a deux ou trois ans. Joli objet des Editions Actes Sud, que je décide récemment d'ouvrir et que je n'ai pas lâché (un «page turner», diraient les Anglo-Saxons). C'est en partie lié, sans doute, au fait que j'ai récemment parcouru le Sud de l'Afrique et que je me suis intéressé à son histoire. Van Reybrouck est un universitaire belge (né en 1971), qui a étudié l'archéologie et la philosophie avant de se tourner à plein temps vers l'écriture. Son point de départ est un litige historique qu'il cherche à élucider. Avec pour protagonistes, à distance, le grand poète symboliste Maurice Maeterlinck, premier Prix Nobel belge de littérature, en 1911, personnalité flamboyante du début du $\mathrm{XX}^{\mathrm{e}}$ siècle européen, et un chercheur et écrivain sud-africain, largement autodidacte, Eugène Marais. Ce dernier s'est intéressé, sur le terrain, à plusieurs familles d'animaux et a publié dans les années 1925-26, en afrikaans dans un journal de son pays, des textes sur la vie des termites dont un livre a été tiré un peu plus tard.

\section{Un ouvrage largement documenté}

Maeterlinck, connu d'abord pour ses œuvres poétiques, a aussi publié des ouvrages naturalistes, dont le très connu «La vie des abeilles» (1901) et, en 1927, «La vie des termites». Dans les années qui ont suivi, de vives critiques ont émané d'Afrique du Sud, accusant Maeterlinck d'avoir plagié en puisant dans les textes de Marais sans en aucune manière donner crédit à ce dernier.

Dans les années 1990, Van Reybrouck s'est passionné pour cette affaire, d'une manière alliant la recherche bibliographique et la précision de l'académique à la motivation du journaliste d'investigation. Cela donne un récit de 400 pages qui vaut le voyage, si je peux dire. Par sa persévérance et quelques coups de chance, l'auteur a rassemblé une large documentation. Il est allé plusieurs fois en Afrique du Sud, surtout dans la région de Pretoria mais aussi au Cap pour rencontrer un biographe d'Eugène Marais.

Il a parcouru la région du Nord-Transvaal où ce dernier a passé des années (à côté de voyages et séjours à l'étranger, y compris pour soutenir les Boers dans leur guerre contre les Anglais). Van Reybrouck avance progressivement, les péripéties de sa recherche de témoins de la vie et de l'époque de Marais sont remarquablement décrites. Poursuite assidue: qu'il s'agisse de documents dans des bibliothèques; d'éléments matériels (fermes - aujourd'hui délabrées - où Marais a vécu quelque temps, objets); de localités et régions où des souvenirs de lui sont présents, y compris par l'intermédiaire de personnes dont les ascendants l'ont connu. La conclusion de ses travaux attentifs reste une vraisemblance seulement (qu'il y a eu plagiat dans une mesure limitée).

\section{Le passé, le présent, l'avenir}

Couplé à cela des descriptions du pays physique, géographique, des paysages, de la faune et flore. Et, autre dimension, observation de l'Afrique du Sud et de ses habitants au moment d'une mutation majeure, l'abolition de l'apartheid et l'arrivée du pouvoir noir, avec le président Mandela en 1994.

Travail de la Commission Vérité et Réconciliation (1996-1998 surtout), ses réalisations remarquables mais aussi ses limites (une grande partie des Blancs n'ont pas voulu participer au processus, ont refusé de se présenter aux invitations/convocations de la Com-

\section{Cela donne un récit de 400 pages qui vaut} le voyage, si je peux dire.

mission). Réflexions sur l'avenir du pays: un racisme inchangé, explicite, perdure dans certains milieux, afrikaner en particulier (l'histoire très mouvementée et difficile des Boers reste, on peut le comprendre, enracinée dans leur mémoire). A quelle vitesse, le temps passant, les mentalités évolueront-elles? Difficile à dire. Restent ainsi des défis majeurs quant au vivre ensemble dans ce pays et au nécessaire "rattrapage», au plan socio-économique et de l'éducation/formation, des Noirs et de autres minorités.

Même si on juge ne pas être grandement concerné par ce qui se passe au sud de l'Afrique, je recommandé cette stimulante lecture pour ses qualités littéraires, de recherche historique et de réflexion sur le passé récent. 